\title{
Desiertos: paisaje, cuerpo, vida y texto en los límites de lo decible*
}

\author{
Catalina Forttes Zalaquett \\ Pontificia Universidad Católica de Valparaíso/FONDECYT \\ Macarena Urzúa Opazo \\ Universidad FinisTerrae-CIDOC/FONDECYT
}

"Viajar entre paisajes muertos en que nada se mueve, nada respira, nada vuela, ni nada suena" Francisco Javier San Román, Desierto y cordilleras de Atacama

El imaginario del desierto es tan destacado en nuestras tradiciones religiosas, literarias y cinematográficas que es difícil pensar en un desierto sin traer a la mente una obra o autor que ha elaborado su propia visión de un medio natural hostil y desprovisto de lo necesario para la vida humana. Desde luego, estos espacios pueden ser ecológicamente muy variados: las arenas surcadas por el Nilo, el blanco enceguecedor del círculo polar, las pampas argentinas que se extienden hacia el horizonte como en alto mar, o inclusive las selvas amazónicas que fueron el escenario de delirantes proyectos de conquistadores y misioneros. Hasta el mismo mar puede percibirse como una suerte de desierto, como en la "Rhyme of the Ancient Mariner" ["Rima del marinero anciano]" de S. T. Coleridge donde el asesino del albatros, transgresor de un pacto sagrado entre el hombre y la naturaleza, ve "Water, water, everywhere, / Nor any drop to drink" ("agua, agua, por todos lados, / y ni una sola gota que beber"; 333). Lo que todas estas representaciones de desiertos tienen en común es un entorno que exterioriza estados espirituales y psicológicos, pone a prueba lo que entendemos por lo humano y cuestiona nuestra forma de aprender y expresar la realidad.

El desierto es así siempre un espacio por descifrar que se construye por medio del relato de quien tuvo que por valentía, vocación o castigo someter su cuerpo a la hostilidad del vacío. La representación del desierto es invariablemente parcial y se configura en nuestra tradición histórica y literaria como una geografía que continuamente se nos escapa y cuya posesión es imposible. El desierto se perpetúa como misterio y objeto de estudio en el afán de comprender para luego nombrar y dominar aquel espacio que se levanta siempre como la antítesis de lo que como cultura hemos definido

\footnotetext{
* La coorganización y presentación de este dossier forman parte de los proyectos Fondecyt de: 1. Macarena Urzúa "Ruinas en el paisaje de la memoria. Recorrido por la producción literaria y cinematográfica chilena de la última década". Proyecto posdoctorado $N^{\circ} 3130371$, período 2013-2015.

2. Catalina Forttes Zalaquett "Sobrevivir la megalópolis: adolescentes, masculinidad y medios en la novela de iniciación latinoamericana, 1960-2011", Proyecto de iniciación № 11121275, período 2012-2013.
} 
como lo civilizado, asentado o conocido. Para fortuna de los individuos de afición citadina hay una larga lista de eremitas, viajeros ilustrados, naturalistas, poetas, cineastas, misioneros y aventureros que han traído de sus periplos relatos que nutren nuestra imaginación. La selección de textos que presenta este dossier aborda la inmensa diversidad de obras literarias, cinematográficas y fotográficas que abordan el tema del desierto desde una mirada latinoamericana.

François Hartog describe en El espejo de Heródoto los "verdaderos" desiertos como aquellos espacios "sobre los cuales no hay nada que decir porque son límites a la vez del espacio y de lo decible" (42). Lo simbólico sería así el resultado de un esfuerzo por describir lo inasible y el encuentro con el desierto involucraría siempre un acto creativo y narrativo. Es entonces, la literatura la que se encarga de darle un lugar al desierto, de relatarlo para luego incluirlo en el discurso de lo conocido, de lo dominable o de la nación. En esta línea, Fermín Rodríguez, uno de los colaboradores del presente dossier, ha afirmado en Un desierto para la nación. La escritura del vacío (2010): "Escribir el desierto fue borrar del paisaje las huellas de los cuerpos fugitivos de la llanura" (197).

El espacio del desierto como pampa, sertão, confín o tránsito hacia otra vida se configura en los trabajos reunidos en este dossier como el espacio de lo innombrable, lo bárbaro, lo que se quiere olvidar o aquello que no se logra codificar o incorporar al relato nacional o, en el caso del texto de Bryan Green, imperial. Pensemos, por ejemplo, en el caso del norte chileno, un espacio todavía en disputa soberana donde los chilenos han enterrado una historia de guerra, explotación y genocidio, pero desde el cual también germinaron los primeros proyectos de organización obrera. Nuestro desierto es un palimpsesto en el que se encuentran enterradas las semillas de nuestros proyectos de izquierda, las huellas de los que pagaron el precio de la guerra del Pacífico, las víctimas de la matanza obrera de Santa María de Iquique, los orígenes coloniales de la fiesta de la Virgen de la Tirana y los huesos de los detenidos-desaparecidos por la dictadura militar. La memoria se construye a partir de restos esparcidos por un territorio que funciona simultáneamente como ausencia y presencia de la historia y que en este dossier intenta ser recuperada a partir de la ficción narrativa, cinematográfica y fotográfica, sin dejar de lado la poesía y los estudios historiográficos sobre el desierto.

Los trabajos aquí reunidos presentan una serie de recorridos por desiertos latinoamericanos y la forma en que figuras como viajeros, misioneros, investigadores, migrantes y turistas interactúan con las especificidades de una geografía que se constituye como un significante siempre elusivo y atado a la mirada del que lo describe. Los desiertos que los investigadores leen por medio de novelas, películas, crónicas e imágenes fotográficas son: los desiertos de Baja California cuando estos eran los confines de Nueva España, el desierto de Sonora en la frontera norte de México donde Roberto Bolaño ambienta los horroríficos crímenes de su novela 2666, los desiertos de los Estados Unidos recorridos por una subjetividad fronteriza o latinoamericana que viaja al "otro lado", el norte Chico chileno, y el sertão brasileño. Estas visiones del desierto (colonizadas y colonizadoras) representan tanto un territorio antiguo como uno nuevo que se construye y se va resignificando, a medida que se inventan formas de habitarlo y de observarlo. 
En su aporte a esta colección, "El trabajo del miedo", el investigador argentino Fermín Rodríguez escribe sobre el desierto retratado en la narrativa de Bolaño como trasfondo de los femicidios de Santa Teresa, la ciudad ficticia de 2666 que representa una muy poco velada alusión a Ciudad Juárez. Rodríguez se enfoca en "La parte de los crímenes", una de las cuatro partes de la novela póstuma publicada en 2004, y lee el paisaje desértico y los espacios urbanos (vertederos, barrios periféricos, maquiladoras) de Santa Teresa como una confluencia de la biopolítica con un mercado neoliberal que dispone de la vida de los desvalidos como un bien que se consume y se desecha. De este modo el estado fallido, el mercado libre y el crimen organizado convierten la ciudad en un vacío, o un desierto, donde prevalece la ley del miedo.

El norte de México es abarcado también por la investigadora mexicana Edith Mora en "Tres circos, tres novelas buscando un lugar en el desierto mexicano: la territorialización de los confines", trabajo que presenta una lectura de tres obras emblemáticas de la llamada "Literatura de Desiertos" que recrean el espacio tanto geográfico como psicológico de la frontera norte. La propuesta de Mora consiste en la configuración de un imaginario para leer las novelas Albedrío (1989) de Daniel Sada, Santa María del Circo (1998) de David Toscana y El circo que se perdió en el desierto de Sonora (2002) de Miguel Méndez a partir del nomadismo y la huida como una forma de habitar y de apropiación del espacio. Los personajes presentados por las novelas que analiza Mora se construyen a partir de la tensión del deseo de habitar el espacio hostil del desierto y la imposibilidad de establecerse. Según el análisis de Mora, el nomadismo como modus vivendi exige una creatividad de supervivencia que la investigadora conceptualiza por medio de un proceso de destrucción, transición y creación mediante el que se territorializan los confines.

La huida hacia el desierto entendido como un espacio de frontera es un tema que se repite en varios de los trabajos presentados aquí. El desierto representa el confín de lo conocido y por lo mismo es el lugar donde la subjetividad es puesta a prueba, tentada, quebrada y fortalecida. Este es el caso del trabajo de Catalina Forttes Zalaquett, "Los desiertos del otro lado: el desierto como espacio formativo en Ciudades desiertas de José Agustín y Road Story de Alberto Fuguet". El desierto, en este caso norteamericano, otorga a los jóvenes latinoamericanos representados en las novelas Ciudades desiertas y Road Story la posibilidad de someter sus cuerpos a un estado excepcional, donde la interacción con los elementos, el tedio de la mirada que se pierde en el horizonte, y la soledad de la carretera permiten experimentar nuevas posibilidades sensoriales. Los desiertos del suroeste y medio oeste norteamericano son los escenarios donde el viaje identitario propio del proceso de formación es ampliado hacia espacios más allá de las fronteras geopolíticas de Latinoamérica. El encuentro del cuerpo con paisajes hasta entonces solo conocidos por medio de la imaginación literaria y cinematográfica de cuño norteamericano pone en tensión elementos constitutivos de la identidad tanto individual como nacional.

El trabajo "'Poseamos el desierto con la mente': la frontera misionera en la narrativa jesuita de los siglos XVII y XVIII" del investigador Bryan Green propone una genealogía del tropo del desierto en la narrativa misionera 
hispanoamericana con un enfoque en la hagiografía jesuita de los siglos XVII y XVIII, la cual estudia en tres casos: la Conquista espiritual hecha por los Religiosos de la Compañía de Jesús en las Provincias del Paraguay, Paraná, Uruguay y Tape (1639) de Antonio Ruiz de Montoya, la Historia de los triunphos de nuestra santa fee entre gentes las mas bárbaras, y fieras del Nuevo Orbe (1645) de Andrés Pérez de Ribas, y la Vida y virtudes de el venerable y apostólico padre Juan de Ugarte (1752) de Juan Joseph de Villavicencio. El trabajo de Green analiza la importancia del espacio del desierto, entendido como confín y frontera, para la realización de un ideal ascético que se remonta a los orígenes del cristianismo en el mundo mediterráneo y que fue actualizado por los jesuitas en la Hispanoamérica colonial. Según Green, la historiografía jesuita presenta a los misioneros de la orden en su lucha contra las adversidades psicológicas y físicas de su apostolado en las fronteras hispanoamericanas como un modelo de ascetismo heroico destinado a la contemplación de lectores laicos con el fin de "poseer el desierto con la mente". Más que la representación de ejemplos de abnegación extrema cuya conducta se esperaba reproducir en el actuar de las clases dominadoras, Green plantea que estas obras sirvieron para mediar la profunda crisis de legitimidad de la soberanía española al definir la virtud como una lucha constante contra los vicios inherentes en el ejercicio del poder en Hispanoamérica. Paradójicamente, en esta visión ética del mundo colonial los vicios y las crisis en el origen de la soberanía española son la ocasión para el ejercicio de un ideal ascético que reafirma la justicia del sistema colonial, en el cual el tropo del desierto resulta esencial.

Macarena Urzúa estudia el desierto por medio del cine, y particularmente en la mirada desde la infancia, en "Desde mi ventana, el desierto en los ojos de la infancia: De jueves a domingo de Dominga Sotomayor". Este artículo trabaja con De jueves a domingo (2012), película que muestra el recorrido en la carretera de una familia a través de la mirada de la protagonista, una niña, Lucía, quien desde su ventana verá la transformación del paisaje, junto a la pérdida del orden familiar, y finalmente el fin de su infancia. A medida que el viaje avanza, observamos la aparición de un paisaje cada vez más desértico y desolado como termina apareciendo la representación de ese espacio: un reflejo de lo vivido.

El trabajo de Irene Depetris Chauvin, "Ecos en el desierto. Paisaje, pueblo y afectividad en Sertão de Acrílico Azul Piscina", película de Karim Aïnouz y Marcelo Gomes estrenada en 2004, explora el territorio inagotable del sertão en parte del imaginario cinematográfico de Brasil. El trabajo alude al rol que ha tenido la representación de este territorio a lo largo de la historia del cine brasilero, partiendo por directores como Glauber Rocha, representante del cinema novo, hasta la reaparición del sertão hacia los años noventa y dos mil con películas como Central do Brasil (2001) de Walter Salles en donde este territorio adquiere un nuevo carácter al aparecer como una alegoría de la nación. Sin embargo, Depetris Chauvin aborda la manera en la que el sertão se ha ido vaciando de significación, y plantea el modo en que Sertão de Acrílico Azul Piscina, el documental analizado aquí, propone volver a pensar el paisaje del sertão desde los afectos. La película realiza un recorrido y va transformando el espacio en una "cartografía emocional", análisis que ofrece revisitar este paisaje desde una reflexión basada no solo en lo contextual e 
histórico, sino también desde un recorrido que incluye el rol de los afectos. Depetris propone incorporar la categoría de lo háptico, tanto como un modo de leer la película así como también del desierto nordestino, el sertão.

La artista y fotógrafa Liz Wells sostiene que al nombrar un lugar le imprimimos ciertas categorías, ya sean geográficas, afectivas, o íntimas, es decir, domesticamos ese espacio. Asimismo, Wells señala que debemos recordar que etimológicamente geografía significa "un dibujo de la tierra": esta grafía adquiere diversas formas como las fronteras, los planos urbanos, los mapas catastrales, entre otros modos de representar y domesticar un territorio: "Geography is concerned with knowledge about place, communicable in various modes, including the pictorial" (Intro.). Así la geografía y el paisaje se relacionan entre sí mediante la imaginación, de manera que escribir sobre el desierto también permite volver a imaginarlo.

Quisiéramos como parte de esta presentación y como objetivo que trasciende este dossier llamar la atención sobre las posibilidades investigativas en el cine y las letras chilenas que otorgan pensar nuestra tradición en relación con el desierto. Uno de los primeros mapas detallados del desierto chileno fue el del viajero italiano Amado Pissis, ya avanzado el siglo XIX ${ }^{1}$. El desierto es así territorio dibujado primero, frontera después y más tarde un paisaje nuestro. El historiador Manuel Vicuña habla del miedo que provocó el desierto a quienes pelearon en la guerra del Pacífico. Así lo expresa el testimonio de un soldado llamado Abraham Quiroz, quien narra su experiencia de la guerra, en una carta a su padre:

Me parece que llegando a mi Patria me voy a encontrar con el Edén, según me lo figuro (probablemente se refiere a Quillota, de donde era natural) con sus campos lo más vistosos, sus hermosos parajes. Cansado estoy de ver desiertos sin aguas o sierras transitables (80).

Para este soldado el desierto no es el espacio de la nación, sino su antesala, ya que al igual que el jardín del Edén, la nación debe ser fecunda.

El desierto chileno es en las primeras décadas del siglo XX uno de los principales focos de trabajo asalariado y proletarización de la mano de obra. El mundo del mineral transforma el desierto en un imán para el hijo de peón, el afuerino y el hombre que ve en el trabajo minero un futuro más allá del universo señorial del Chile anterior a la reforma agraria. El desierto se configura así en el imaginario nacional del momento como un espacio explotable, fecundo para capitales extranjeros y el sustento de una belle époque de la que hoy quedan en parte oficinas salitreras y placillas mineras ruinosas, junto con edificios afrancesados y líneas de tren abandonadas. En este contexto de los trabajadores del mineral se verá aparecer el germen del capital político de un actor fundamental de esta coyuntura social, Emilio Recabarren, quien llevará la dirección del primer movimiento revolucionario de izquierda nacional. Las luchas sociales, la organización obrera y el abuso

1 Pissis publica en París la Geografía física de la república de Chile, 1876. 
de los capitales extranjeros han sido representados en la literatura por el Premio Nacional de Literatura y éxito editorial Hernán Rivera Letelier y en el cine por el "Nuevo Cine Chileno", denominación que incluye principalmente a los cineastas comprometidos de los años sesenta (Helvio Soto, Miguel Littin, Aldo Francia, entre otros). Con el propósito de reconstruir una historia de lucha social los cineastas del Nuevo Cine Chileno se remontan a la guerra del Pacífico, la consecuente explotación minera y la represión y masacre de los primeros obreros organizados, en películas como Caliche sangriento de Helvio Soto (1969) y el documental Escuela de Santa María de Iquique (1969) de Claudio Sapiaín. Esta es una historia que rescatará también Diamela Eltit en el cambio de siglo con su novela Mano de obra (2002) en la cual antecede las representaciones de la explotación neoliberal de trabajadores de supermercado con viñetas que hacen alusión a los movimientos obreros de comienzos de siglo.

En los años ochenta, el poeta Raúl Zurita en su poemario Purgatorio (1979) configura todo el territorio nacional como una herida, una llaga, en cuerpo perdido y encontrado para ser sublimado. Dentro de los apartados del texto "El desierto de Atacama" se destaca al personificar el desierto de forma metonímica con el cuerpo de las víctimas de la dictadura. Como señala William Rowe en "El espacio americano en la obra de Raúl Zurita", en estos poemas puede verse cómo el desierto deviene en la piel, de un cuerpo sobre el cual la tortura no puede entrar, ya que "desplazamiento de la tierra hacia lo no humano le permite convertirse en una piel más, contenedora del cuerpo y sitio de la percepción, y de esta manera puede ser un espacio no violado en el imaginario" (193).

i. Suspendido sobre el cielo de Chile diluyéndose entre auras

ii. Convirtiendo esta vida y la otra en el mismo Desierto de Atacama aúrico perdiéndose en el aire

iii. Hasta que finalmente no hay cielo sino Desierto de Atacama y todos veamos entonces nuestras propias pampas fosforescentes carajas encumbrándose en el horizonte (33)

El cine de la transición también contextualizará los horrores de la dictadura en el desierto de Atacama, tal es el caso de Amnesia (1994) de Gonzalo Justiniano, donde lo vivido en el desierto se presenta como trauma que se resiste a ser narrado, o bien como un espacio abierto hacia el cual huir de la marginalidad de la periferia urbana en la película Caluga o menta (1990) del mismo autor. En el cine más reciente, el territorio del desierto se reconfigura como un escenario para historias camineras o de carreteras en las películas Crystal Fairy \& The Magic Cactus (2014) de Sebastián Silva y De jueves a domingo (2012) de Dominga Sotomayor. En estas películas el territorio deviene en texto y también en un contenedor de los residuos de un pasado difícilmente narrable como en el caso de los documentales Nostalgia de la luz (2010) de Patricio Guzmán, Mi vida con Carlos (2010) de Germán 
Berger y Las niñas Quispe (2014) de Sebastián Sepúlveda. En ese sentido el espacio del desierto que es descrito, escrito y filmado, puede verse como una geografía que en lugar de responder, interroga.

La desaparición de cuerpos como resultado de un esfuerzo por enterrar las víctimas de la historia tiene en la narrativa reciente un correlato psíquico, ya que se representa el desierto como el espacio donde se manifiesta el síntoma de un cuerpo por años invisibilizado. Este es el caso de la novela de Diego Zúñiga, Camanchaca, en donde el viaje en carretera por el camino entre Iquique y Tacna, acompañado por un padre siempre ausente se ofrece como el espacio psíquico para hacerse cargo de las encías sangrantes de un comedor compulsivo. Los trabajos más recientes de Alberto Fuguet, Cortos (2004) y Missing: una investigación (2011) también incluyen el fantasma de la desaparición y la búsqueda del y lo perdido en el desierto. Así es como Simón, el protagonista de "Road Story" el cuento más largo de Cortos, sale en búsqueda de sí mismo por los desiertos de Estados Unidos y en Missing el mismo Fuguet busca y encuentra a su tío perdido en Las Vegas, la ciudad más brillante del desierto de Nevada. Fuguet explora una figura antes retratada por Francisco Mouat en El empampado Riquelme (2001) desde la ficción y la crónica. El empampado es un fantasma que acecha la literatura de Fuguet, principalmente porque perderse en el desierto significa renunciar a una comunidad o bien que una comunidad haya dejado de buscarlo a uno. Los restos de Riquelme, un hombre que se creía desaparecido hace cuarenta años, aparecen perdidos en el desierto de la misma forma en que su tío aparece en Las Vegas. La historia del empampado que retoma e intenta reconstruir Mouat alegoriza la relación de una nueva subjetividad con el espacio del desierto. Nos referimos a una mirada dispuesta a internarse en un espacio hostil de nuestra historia y psiquis con el fin de buscar en ese territorio los vestigios del cuerpo, los restos así como los retazos de un relato que el desierto pareciera guardar en sí.

\section{Obras citadas}

Abraham Quiroz, "Epistolario inédito de su campaña como soldado raso durante toda la Guerra del Pacífico. 1879-1884". Dos soldados en la Guerra del Pacífico. Buenos Aires: 1974. En: Vicuña, Manuel. La imagen del desierto de Atacama (XVI-XIX). Del espacio de la disuasión al territorio de los desafíos. Santiago: Editorial USACH, 1995.

Abrams, M.H. The Norton Anthology of English Literature (Sixth Edition). New York: Norton \& Company, 1993.

Hartog, François. El espejo de Heródoto: ensayo sobre la representación del otro. Buenos Aires: Fondo de Cultura Económica de Argentina, 1980.

Rodríguez, Fermín. Un desierto para la nación. Buenos Aires: Eterna Cadencia, 2010.

"Estanislao S. Zeballos: un desierto para la nación". Relics \& Selves: Articles. Iconographies of the National in Argentina, Brazil and Chile 1880-1890. Web. Junio 2014 <http://www.bbk.ac.uk/ibamuseum/ texts/Rodriguez01.htm>

Rowe, William. Hacia una poética radical: ensayos de hermenéutica cultural. Rosario: Beatriz Viterbo, 1996.

San Román, Francisco J. Desierto y cordilleras de Atacama. Santiago: Imprenta Nacional, 1896 [DIBAM, 2012]. Citado en Vicuña, Manuel. La imagen 
del desierto de Atacama (XVI-XIX). Del espacio de la disuasión al territorio de los desafíos. Santiago: Editorial de la USACH, 1995.

Vicuña, Manuel. La imagen del desierto de Atacama (XVI-XIX). Del espacio de la disuasión al territorio de los desafíos. Santiago: Editorial de la USACH, 1995.

Wells, Liz. Land Matters: Landscape Photography, Culture and Identity (International Library of Cultural Studies). Introduction. London, New York: I.B.Tauris, 2011. Kindle Edition.

Zurita, Raúl. Anteparaíso. Santiago: Editores Asociados, 1982.

\section{Referencias}

Amnesia. Dir. Gonzalo Justiniano, Chile 1994.

Caliche Sangriento. Dir. Helvio Soto, Chile. 1969.

Caluga o menta. Dir. Gonzalo Justiniano, 1990.

Crystal Fairy and The Magical Cactus. Dir. Sebastián Silva, Chile, 2013.

De jueves a domingo. Dir. Dominga Sotomayor, Chile, 2012

Eltit, Diamela. Mano de obra. Santiago, Seix Barral, 2002.

Escuela de Santa María de Iquique Dir. Claudio Sapiaín, Chile, 1969.

Fuguet, Alberto. Cortos. Santiago: Alfaguara, 2004.

Missing: una investigación. Santiago: Alfaguara, 2011.

Las niñas Quispe. Dir. Sebastián Sepúlveda, Chile, 2014.

Mi vida con Carlos. Dir. Germán Berger, Chile, 2010.

Mouat, Francisco. El empampado Riquelme. Santiago: Lolita Editores, 2011.

Nostalgia de la luz. Dir. Patricio Guzmán, Chile, 2010.

Zúñiga, Diego. Camanchaca. Santiago: Calabaza del Diablo, 2010. 